\title{
A SIX-LEGGED RAT
}

\author{
SARA B. CONROW \\ From The Wistar Institute of Anatomy and Biology, Philadelphia \\ FIVE FIGURES
}

During February, 1915, a male albino rat (Mus norvegicus albinus) with six legs and a tail in a fixed position over its back, appeared in the rat colony of The Wistar Institute. Its ancestry was not known. Its external appearance while living may be seen in figures 1 and 2, and its appearance after death in figure 3.

Two short, deformed legs hung down loosely between the two normal hind legs. They dragged on the ground and were not under the control of the animal. The base of the tail was fixed firmly in an upward curve; the rest of the tail hung loosely on one side or the other of the body and also was not under the control of the animal. There were two sets of external genitals and a false anus at the left of and ventral to the functional anus. The animal was mated but never bred. It lived for about fifteen months in good health, when, seeming to be sick, it was killed on May 26, 1916, and examined. Its body weight was 249 grams, body length $210 \mathrm{~mm}$., and its tail length about 192 $\mathrm{mm}$.

The anterior part of this rat was normal as far caudad as the diaphragm, beyond which there were indications of doubling. The spleen was large. On the right side in normal position was a large kidney, while low down on the left side was the rudiment of a kidney (no kidney was found in normal position on the left side). The bladder was a double structure with a perforated, intermediate septum; there was an opening through each of the two penes. On the right side were one large testis, one very small testis, and one epididymis; on the left side also were one large testis, one very small testis, and one epididymis. 
Skeletal conditions in the pelvic region may be seen in figures 4 and 5 .

The vertebral column remained single throughout and was normal as far as the fifth lumbar vertebra. The fifth and sixth
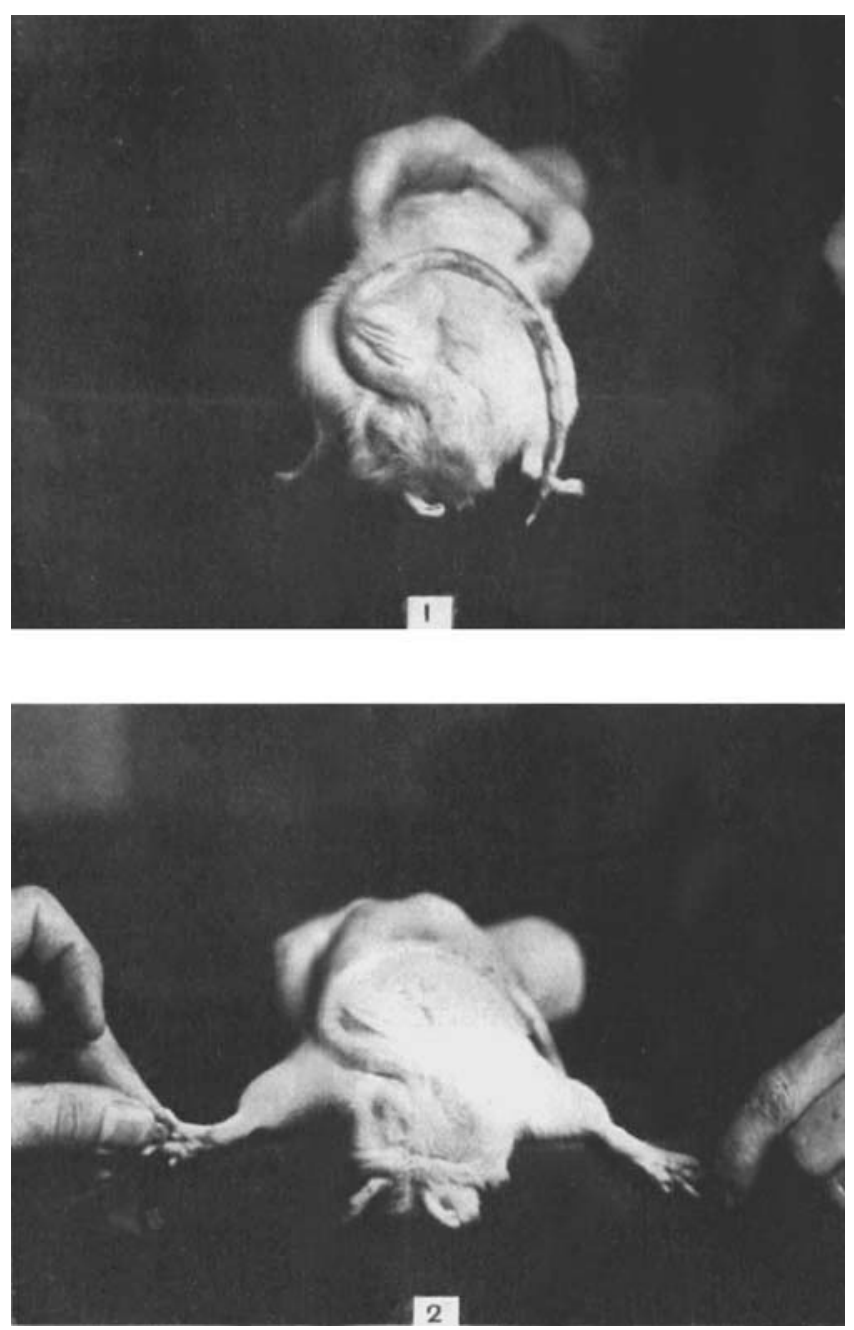

Figs. 1 and 2 Caudal aspect, showing normal hind legs, rudimentary hind legs, scrota and curve of tail. 
lumbar vertebrae were slightly deformed and twisted. The four sacral vertebrae were more deformed; the first had the left. portion of the fused pelvic girdles attached to its left transverse process, while the second had the right portion attached to its right transverse process. The six proximal, caudal vertebrae were more or less deformed and were fixed firmly in a dorsal curve which turned to the left over the animal's back. 篓 The

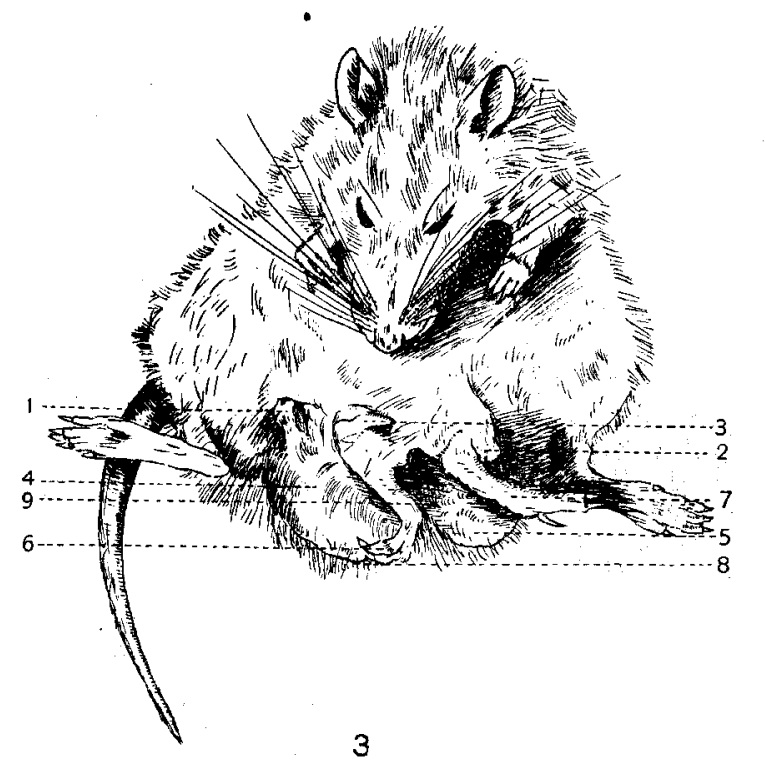

Fig. 3 Ventral aspect; 1 , penis, right side; 2 , penis, left side; 8 , papilla; 4 , scrotum, right; 5 , scrotum, left; 6 , right rudimentary leg; 7 , left rudimentary leg; 8 , anus (position under); 9 , false anus.

fused pelvic girdles and bones of the deformed legs will be described later.

The structures most concerned in the duplication in this rat were the pelvic girdle, hind legs, and genital organs. The two fused pelvic girdles showed three distinct parts, namely, a right nearly normal part, a left part $2 \mathrm{~mm}$. shorter than the right and proportionally smaller, and a slender, irregular bar of bone 27.4 $\mathrm{mm}$. long with ends flattened dorso-ventrally (figs. 4 and 5). These three were arranged as follows: The left part held a position 
further forward than the right, the crest of its ilium being $7 \mathrm{~mm}$. anterior to the crest of the right ilium. The right and left parts did not meet in the median line in the symphysis pubis but their posterior ends were separated laterally a distance of more than $2 \mathrm{~cm}$. Bridging this space was the slender bar of bone firmly

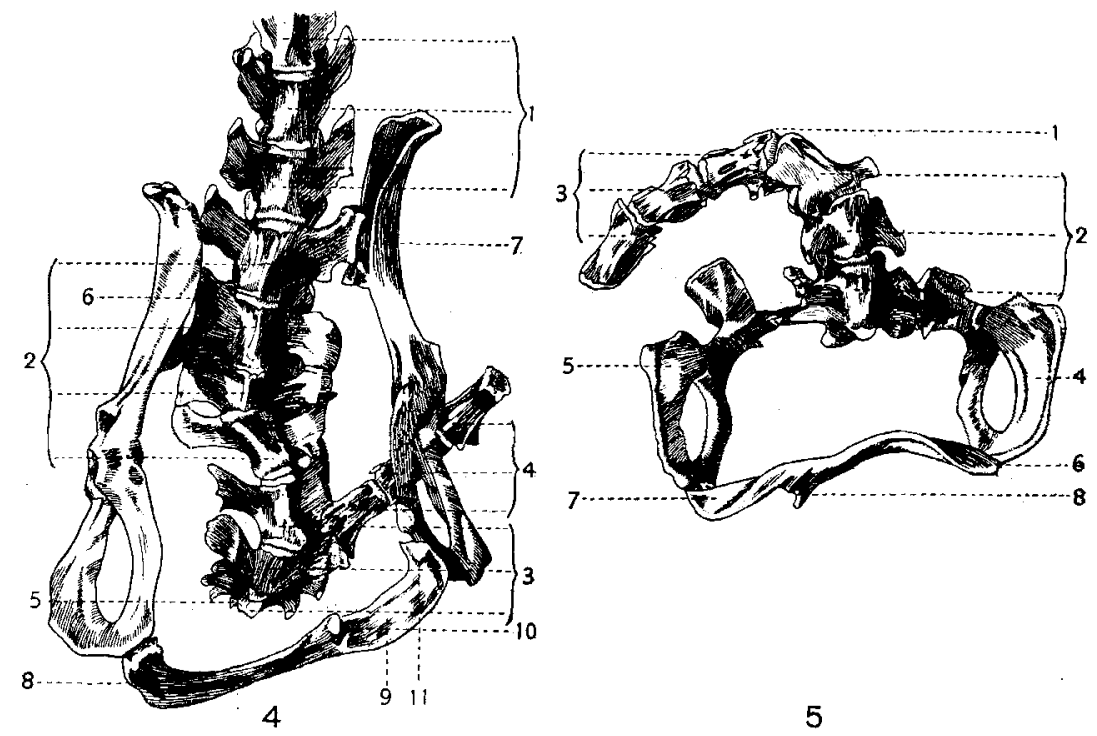

Fig. 4 Ventral aspect; 1 , fourth, fifth and sixth lumbar vertebrae; 2 , four sacral vertebrae; 3 , first, second and third caudal vertebrae; 4 , sixth, seventh and eighth caudal vertebrae; 5 , curve of caudal vertebrae; 6 , attachment of right part of fused pelvic girdles; 7 , attachment of left part of fused pelvic girdles; 8 , right deformed ilium; 9 , left deformed ilium; 10 , point of attachment of right rudimentary leg; 11 , point of attachment of left rudimentary leg.

Fig. 5 Caudal aspect; 1 , dorsal side; 2 , third, fourth and fifth caudal vertebrae; 3 , sixth, seventh and eighth caudal vertebrae; 4 , right part of fused pelvic girdles; 5 , left part of fused pelvic girdles; 6 , right deformed ilium; 7 , left deformed ilium; 8 , point of attachment of right rudimentary leg.

attached by its flattened ends to the posterior parts of the right and left pubic bones. It seemed to be composed of two deformed fused ilia. From the ventral side of this bar hung the two short, deformed legs, one from its left end and one from a point at the left of the median line. They were attached by ligaments to slight pits in the bar at these points, and were scarcely more 
than deformed feet, though each had two curved, slender bones suggesting the tibia and fibula. In addition to these bones each rudimentary leg had a deformed os calcis and the rudiment of another bone of the tarsus; in the right leg there were four metatarsal bones and four digits, all more or less deformed; in the left leg there were three metatarsal bones and three digits, less deformed than in the right, but not quite normal.

The two sets of external genitals were normally placed with reference to the two pairs of legs; namely, one set for the right normal hind leg and the right deformed leg, and the other set for the left deformed leg and the left normal hind leg. The two penes were $2.5 \mathrm{~cm}$. apart and there was a fleshy papilla about midway between them. Internal conditions here have been noted.

Looking at the double portion of this animal it is seen that the right component is more fully developed than the left and that it is nearly in normal position, while the left component is wholly at the left of the median line. The two parts of the right pelvic girdle are larger than those of the left component, the right part being nearly normal and the left part being the larger of the two fused ilia and having a more pronounced acetabulum. The left leg of the right component (the right deformed leg) has more indications of tibia and fibula and more bones in the foot than has the other deformed leg. Also the functioning anus is associated with parts of the right component.

This rat apparently corresponds to the dipygus type of human monster, although its vertebral column remains single throughout. Examples of this type have been described by Gould and Pyle ('97) and by Wilder ('04). In such monsters the pelvis and the lower part of the spinal column are more or less double. Wilder ('04) describes several human monsters of this type. He gives first Wells' case of Mrs. B. Here the duplication began at the third lumbar vertebra. There were a fused double pelvis, two pairs of legs (the inner ones somewhat reduced in size), two sets of external genitals, two bladders, two ani, and two rectums. Heschel's case was of a girl seventeen years old with double parts below the second lumbar vertebra. In the case of 
Rlanche Dumas the pelvis appeared incompletely double and there were two extra legs, two distinct sets of genitals, and a rudimen tary mamma just above the pubes. Others described by Wilder ('04) which were not strictly of the dipygus type were as follows: Jean Baptista dos Santos was wholly normal save in the pelvic region. Here there was an exact duplication of the external genitals and a median third leg, which was double and symmetrical, depended from an extra, median pelvic bone. There were four testes present. (Gould and Pyle ('97) in describing this case say that here there was possibly a double bladder commu$r$ sating by an imperfect septum.) Bechlinger's case was that of a female counterpart of dos Santos. The genitals were duplicated, a third leg was attached to a continuation of the processus coccygeus of the sacrum, and there were two rudimentary mammae close together above the pubes. In the case of Louise L: there were two atrophied legs on a rudimentary pelvis attaiched ventrally to the normal pelvis, with two rudimentary mammae at the insertion of the legs. There was no duplication of the genital organs.

Gould and Pyle ('97), besides describing these same monsters, give also examples of differing degrees of duplication in the posterior part of both males and females, but the cases already cited correspond most nearly to conditions found in the male albino rat which has been described.

\section{LITERATURE CITED}

Gould ANd Prue 1897 Anomalies and curiosities of medicine. W. B. Saunders, Philadelphia, pp. 192-198.

Wirder, H. H. 1904 Duplicate twins and double monsters. Am. Jour. Anat., vol. 3, p. 387. 